\title{
Research Paper: Awareness of Medical Students of Gonabad University About Nutrition \& Food Preservation in Disasters
}

\author{
Hamed Biglari', Mahsa Hami², Ahmadreza Yari ${ }^{3}$, Mohsen Poursadeghiyan ${ }^{4}$, Mehrdad Farrokhi ${ }^{*}$ \\ 1. Department of Environmental Health Engineering, School of Health, Gonabad University of Medical Sciences, Gonabad, Iran. \\ 2. Department of Humanities, Firoozkooh Branch, Islamic Azad University, Firoozkooh, Iran. \\ 3. Research Center of Environmental Pollutants, Qom University of Medical Sciences and Health Services, Qom, Iran. \\ 4. Research Center in Emergency and Disaster Health, University of Social Welfare and Rehabilitation Sciences, Tehran, Iran
}

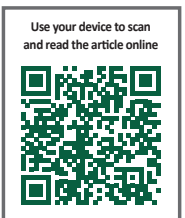

Cittation: Biglari H, Hami M, Yari A, Poursadeghiyan M, Farrokhi M. Awareness of Medical Students of Gonabad University About Nutrition \& Food Preservation in Disasters. Health in Emergencies and Disasters Quarterly. 2017; 2(3): 133-138. https://doi.org/10.18869/nrip.hdq.2.3.133

https://doi.org/10.18869/nrip.hdq.2.3.133

Article info:

Received: 29 Oct. 2016

Accepted: 31 Jan. 2017

\section{Keywords:}

Awareness, Nutrition, Food preservation, Disaster, Gonabad

\begin{abstract}
A B S T RACT
Background: Healthy and hygienic foods should be available for healthy life of humans in all circumstances. This issue will be more important when a disaster occurrs. Iran is among high risk natural disaster countries, that should be always prepared. The present study aimed to evaluate the awareness of Gonabad University Medical students about nutrition and food preservation at times of disaster.
\end{abstract}

Materials and Methods: This cross-sectional and descriptive study was conducted on 360 students out of 1800 Medical Sciences students of Gonabad University who were selected by stratified random sampling method in 2016. A self-designed questionnaire consisting of 10 questions with acceptable validity and reliability was used with Cronbach alpha coefficient of 0.8. Finally, the data were analyzed by 1-sample t-test and Mann -Whitney test through SPSS 16.

Results: The results showed that $39 \%, 35.5 \%$, and $25.5 \%$ of the participants had a good, moderate, and low level of awareness about nutrition and preservation in disasters, respectively. No significant difference was observed between genders $(\mathrm{P}>0.05)$, and fields of study with regard to their awareness $(\mathrm{P}=0.002)$.

Conclusion: It was found that the students' awareness about nutrition and food preservation at times of disaster was poor. Thus, to achieve a successful disaster management, it is recommended that an appropriate instruction manual of nutrition and food preservation be prepared by disaster response agencies and be taught for the guidance of students.

\section{Introduction}

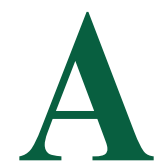

vailability of the healthy and hygienic foods is imperative for healthy life of humans in all circumstances [1]. This issue will be more important when a disaster occurs. Various phenomena like earthquakes, landslides, volcanic eruptions, floods, hurricanes, tornadoes, blizzards, tsunamis, cyclones, fires, transport accidents, industrial accidents, oil spills, and nuclear explosions/ 
radiation are all natural or man-made disasters that could kill thousands of people [2]. Some consequences of these disasters include deserting the residential areas, shortage of food, transport system shut down, and collapse of social structure. There are several parameters associated with food crises, involving extreme weather, natural disasters, economic problems, prolonged wars, fire, water shortage, and sometimes a combination of these factors [1]. Since it is predicted that disasters will continue to happen, governments should plan relief programs in advance by establishing national organizations [3]. Thus, it is very important to be ready and confront possible events (disasters).

The tasks of disaster and famine relief organizations are divided into before crisis and during crisis [4]. Since 1980, the food crises have apparently increased as the whole world suffers annually from 50 to 80 food crises after 2000 . Population health is directly related to food safety during the disasters, as it might cause serious problems such as variety of food-borne diseases [5]. At these moments, countless people can become sick or even die as a result of unhygienic food consumption; this indicates the need for an increased focus on food safety. Adequate planning, preparation, and anticipation like preparing safe food and water, are the main duties of relevant organizations to control such crises and their consequences [6].

In such disasters, the preventive actions can affect the nutritional status of people, duration and extent of the disaster, and the capacity of food production in the affected regions. Therefore, some major responsibilities of states in response to disasters are the empowerment of afflicted subjects by preparing, supporting, and rebuilding food supplies [7]. Quality of crisis prevention and management is largely associated with organizational factors [8]. Crisis management requires the use of health care professionals who have enough knowledge about these situations in various fields. One of the pivotal elements to minimize the damages caused by improper food supply in regions affected by the crises is the level of preparation and knowledge of such experts [9].

In other words, training courses on how to response the crises should be held to raise awareness among experts and officials. In this regard, students should take some courses in the field of crisis management to meet the mentioned needs within their curriculum. Therefore, this study aimed at studying the awareness of Gonabad University Medical students about nutrition and food preservation at times of disaster.

\section{Materials and Methods}

This cross-sectional and descriptive study was conducted on 360 students (43 students more to reduce the risk of loss of response to the questionnaires, computed based on minimum sample size required by Cronbach alpha value as 317 students) out of 1800 Medical sciences students at Gonabad University in 2016. The sampling was done by stratified random sampling method from different genders and fields of study, i.e. six groups of health fields according to previous studies. Students enrolled in this study were studying for 2-4 years at Gonabad university. The data collection tool was a selfdesigned questionnaire consisting of 10 questions. The validity of the questionnaire as the content validity was confirmed by the experts and its reliability using internal consistency method (Cronbach alpha coefficient of $0.80)$. The questionnaire was designed in two sections; a demographic section (age, gender, educational level, and field of study ) and 10 questions about the students' awareness on nutrition and food preservation at times of disaster. With regard to the level of awareness, each correct answer would score " 1 " and wrong answer " 0 ." The general context of the questions was about the type of food, food safety recommendation, main foods supply, nutritional needs, preparing hygienic food and vegetables, food storage and food expiration date, or contamination. Finally, the data were analyzed by Kruskal-Wallis test through SPSS version 16.

\section{Results}

Female and male students constituted equally (50.50\%) in the sample. The selected students were from faculties of Health (23.25\%), Medicine (18.31\%), Nursing (17.73\%), Midwifery (14.53\%), Laboratory Sciences (15.98\%), and Radiology (10.17\%). A total of 344 students answered to questionnaires and at the following results have been reported. Table 1 presents the respondents' answers to the questions about nutrition and how to store food in crises. With regard to the questions about level of awareness, standard deviation (SD) and rate of the response were calculated. Question No.7 (food stuff after settlement of the victims) had the lowest rate of response $(39.5 \%)$ and question No. 11 (the main sideeffects of storing food stuff in unhealthy condition) had the highest rate of respondents $(80.3 \%)$ (Table 2). Afterward, a specific ratio was compared with a constant number and it was assumed that the ratios were equal to 0.5 (the expected response rate in the case of random answering or an equal ratio of the individuals who were aware or not aware). It was found that this hypothesis 
Table 1. Mean score of awareness level of nutrition and how to store food stuff in crises based on gender

\begin{tabular}{|c|c|c|c|}
\hline \multirow{2}{*}{ Variable } & \multicolumn{2}{|c|}{ Gender } & \multirow{2}{*}{ Sig. } \\
\hline & Women & Men & \\
\hline Awareness & 179.95 & 164.05 & 0.325 \\
\hline
\end{tabular}

Table 2. Frequency rate of awareness level of nutrition and how to store food stuff in crises

\begin{tabular}{ccc}
\hline Variable & No. & $\%$ \\
\hline Low (0-4) & 94 & 27.4 \\
Moderate (4-6) & 100 & 29 \\
High (6-11) & 150 & 43.6 \\
\hline & & $\begin{array}{c}\text { Itealth in } \\
\text { Emergencies and Dlisasters [Oluarterly }\end{array}$
\end{tabular}

was not supported and, therefore, the respondents had enough knowledge to answer all the questions. In addition, the results showed that students' mean awareness score, $\mathrm{SD}$, and variation range about nutrition and storing food stuff in crisis were 5.87, 2.02, and 1-11 respectively. Taking into account that total awareness score $\geq$ 6 was considered as the level of acceptable awareness, respondents' awareness about nutrition and the way of storing food stuff in critical condition was a little less than this level. Mann-Whitney test showed that there was no significant difference between male and female students with regard to their awareness $(\mathrm{P}=0.667)$.

In addition, with respect to the awareness level, the students were categorized in two groups of above the fourth year and below the fourth year of the program. Moreover, Kruskal-Wallis test indicted a significant difference between the faculties regarding their level of awareness. So that the level of awareness was highest in the Faculty of Hygiene and lowest in the Faculty of Radiology.
Eventually, level of awareness was examined based on sex of the participants and no significant difference was observed $(\mathrm{P}>0.05)$.

\section{Discussion}

According to the results obtained from the present study, good awareness on nutrition and food stuff storage in crisis was observed among less than $39 \%$ of the students (Tables 3 \& 4). Concerning emergencies, Ghahfarokhi et al. in 2012 conducted a study (with emphasis on a flood occurred in Shahrekord) about the level of awareness in the experts of environment health-food hygiene. They found that the participants had significant difference in awareness before and after training courses. Also education level, work place and awareness level of foodstuff showed a significant association. Moreover, there were no significant relationships between the awareness level and age and work experience in clinics [9]. Dargahi et al. carried out a research on the students

Table 3. Mean score of awareness level of nutrition and how to store food stuff in crises in relation to the faculties

\begin{tabular}{cccc}
\hline Faculties & No. & Awareness Level & Sig. \\
\hline Medical & 63 & 172.99 & 0.002 \\
Midwifery & 50 & 161.68 \\
Nursing & 61 & 184.24 & 210.95 \\
Hygiene & 80 & 143.90 & 115.31 \\
Laboratory sciences & 55 & & $\begin{array}{c}\text { Illealth in } \\
\text { Emergencies and Disasters Oluarterly }\end{array}$
\end{tabular}


Table 4. Students' awareness level of nutrition and how to store food stuff in crisis (1-sample t-test)

\begin{tabular}{|c|c|c|c|c|c|}
\hline Questions & Awareness & No-Awareness & $\%$ & SD & Sig. \\
\hline $\begin{array}{l}\text { What type of food would you recommend during the early } \\
\text { hours of crisis? }\end{array}$ & 174 & 170 & 50.5 & 0.502 & 0.002 \\
\hline $\begin{array}{l}\text { Which one of the following recommendations is suitable in } \\
\text { crisis? }\end{array}$ & 191 & 153 & 55.5 & 0.497 & 0.002 \\
\hline $\begin{array}{l}\text { Which one of the following recommendations is not suitable } \\
\text { in crisis? }\end{array}$ & 204 & 140 & 59.3 & 0.493 & 0.002 \\
\hline $\begin{array}{l}\text { Which are the main foods supply the nutritional needs of the } \\
\text { survivals in crisis afflicted regions? }\end{array}$ & 225 & 119 & 65.4 & 0.477 & 0.002 \\
\hline $\begin{array}{l}\text { How long (minutes) the food must be boiled to ensure it is } \\
\text { safe for eating? }\end{array}$ & 124 & 220 & 36.0 & 0.684 & 0.002 \\
\hline $\begin{array}{c}\text { How long (minutes) vegetables should remain in solution } \\
\text { before eating? }\end{array}$ & 143 & 205 & 41.5 & 0.492 & 0.002 \\
\hline $\begin{array}{l}\text { After settling the displaced population, which food stuff } \\
\text { should be supplied on weekly bases? }\end{array}$ & 133 & 211 & 38.6 & 0.490 & 0.002 \\
\hline What do we mean by dry food stuff during crises? & 180 & 164 & 52.3 & 0.499 & 0.002 \\
\hline $\begin{array}{l}\text { Should the sterilized milk with six months longevity be con- } \\
\text { sumed immediately after opening its package? }\end{array}$ & 159 & 185 & 46.2 & 0.501 & 0.002 \\
\hline $\begin{array}{l}\text { Is sterilize milk a good replacement for pasteurized milk given } \\
\text { that it can be stored in ambient temperature? }\end{array}$ & 211 & 133 & 61.3 & 0.487 & 0.002 \\
\hline $\begin{array}{l}\text { Is decay of food stuff a major consequence of storing food in } \\
\text { unhygienic situation? }\end{array}$ & 277 & 67 & 80.5 & 0.399 & 0.002 \\
\hline
\end{tabular}

in Kermanshah to evaluate their levels of awareness and attitudes toward food hygiene and safety. Their results indicated good awareness for $46 \%$, moderate awareness for $48 \%$ and low awareness for $4.5 \%$ of the students. They did not found any significant correlations between some factors such as age, education level, gender, and faculty with awareness and attitudes of the students on food hygiene and safety [10]. The participants from high school students in the USA and students at University of Missouri had acceptable awareness toward food-borne diseases [11]. Imani et al. (2011) performed a descriptive and cross-sectional study on 250 nurses entitled "Nurses' awareness about crisis management and the pertinent factors." According to their results, very good awareness of crises management was found only among $3.2 \%$, good awareness in $16.6 \%$, moderate awareness in $52.3 \%$ and low awareness in $27.9 \%$ of nurses. They demonstrated a positive correlation between the level of awareness with type of work shift, membership in crisis committee, the role in crisis and education level [12]. In 2012, in a similar research entitled "surveying readiness of obligatory service soldiers regarding health measures in crisis in Malek Ashter Military Base, Arak, Iran,” by Vosoughi Nayari on 190 soldiers, it was revealed that $43 \%$ of soldiers had good awareness, 46\% moderate awareness, 11\% low awareness. Also, 50 had neutral attitudes toward health issues in crises. No significant difference was seen between readiness and awareness on crises and education level and age among the subjects $(\mathrm{P}=0.05)[13]$.

The analyses of the questionnaire demonstrated that the highest $(80.4 \%)$ and the lowest $(36.8 \%)$ levels of awareness were related to adverse effects of foodstuff storage in unhygienic condition and the time required for boiling canned foods, respectively. It can be concluded that one of the strategies to manage health problems and control the transmission of diseases is the promotion of knowledge on nutrition and food hygiene in crises. As well, regarding the results, good to moderate levels of awareness were found among $73 \%$ of the subjects; this rate is a good level of awareness of the population under study. In summary, the insertion of educational programs in different forms (such as pamphlets, formal credits, etc.) within curriculum seems to be necessary for increasing the awareness levels and achieving higher quality services [14]. 


\section{Conclusion}

It is necessary to promote awareness of people, especially Medical and Paramedical students as health stuff in disasters about nutrition and food preservation, that results in prevention of food-borne diseases and preservation of food and environment against contamination. The study result indicate that students' awareness about nutrition and food preservation at times of disaster is poor and training is recommended to achieve a successful disaster management. It is recommended that an appropriate instruction manual of nutrition and food preservation should be prepared for the guidance of students by disaster response agencies.

\section{Acknowledgments}

This research was partially funded by the Student Research Committee of Gonabad University of Medical Sciences (GN: 96/13). The authors are grateful to Mr. Reza Rostami for his technical support. All authors were contributed equally to prepare this paper

\section{Conflict of Interest}

The authors declared no conflicts of interest.

\section{References}

[1] Rostami R, Nafez AH, Falahi H, Mohammadi MM, Jamshidi Kh, Lotfi S, et al. [Surveying awareness of the students of Kermanshah university of medical sciences about nutrition and storing food stuff in crises (2016) (Persian)]. Research Journal of Applied Sciences. 2016; 11(7):563-6. doi: 10.3923/ rjasci.2016.563.566

[2] Farrokhi M, Dolatabadi ZA, Pakjouei S, Pouyesh V. [Review paper: Approaches to post-disaster environmental recovery (Persian)]. Health in Emergencies and Disasters. 2016; 1(2):6570.

[3] Brown BJ. Disaster preparedness and the United Nations: Advance planning for disaster relief. Geneva: United Nations Institute for Training and Research; 2013.

[4] Kumar S, Havey T. Before and after disaster strikes: A relief supply chain decision support framework. International Journal of Production Economics. 2013; 145(2):613-29. doi: 10.1016/j.ijpe.2013.05.016

[5] Azizi SA, Eskandari S, Bavandpour E, Veisi N, Mohammadi MM, Lotfi S, et al. Evaluation of Kermanshah university of medical sciences students' knowledge and attitudes regarding health measures in emergency situations (2016). International Journal of Pharmacy \& Technology. 2016; 8(3):18941-9.
[6] Victoria LP. Community-based disaster management in the Philippines: Making a difference in people's lives. Metro Manila: Center for Disaster Preparedness; 2011.

[7] Farajzadeh D, Soofiabadi Gh. [Surveying nutritional problems in Sepah during the war (Persian)]. Paper presented at: The Military Health Conference. 18-19 May 2002; Tehran, Iran.

[8] Vosoughi Naieri M, Askari M, Jahed Gh, Dargahi Gh, Golestanifar H, Parastar S. [Surveying awareness level and attitude of the students of Tehran university of medical science about health measures in emergencies (Persian)]. Journal of Rescue and Relief. 2012; 4(2):43-52.

[9] Banaieh Ghahfarokhi B, Jazayeri R, Pishkar AR, Khalili M, Karami MH, Kolahi M. [Surveying awareness of environment hygiene health about food stuff hygiene in crises with emphasis on Shahrekord Flood in 2012 (Persian)]. Paper presented at: the $16^{\text {th }}$ National Conference of Environment Health. 1-3 October 2013; Tabriz, Iran.

[10] Dargahi A, Asadi F, Hashemian AH, Sharafi K, Amirian T, Mohammadi M. [Awareness and attitude of the students of Kermanshah university of medical science about food stuff hygiene (A cross-section study) (Persian)]. Nasim-e Tandorosti. 2014; 2(3):1-8.

[11] Unklesbay N, Sneed J, Toma R. College students' attitudes, practices, and knowledge of food safety. Journal of Food Protection. 1998; 61(9):1175-80. doi: 10.4315/0362-028x-61.9.1175

[12] Imani E, Hosseini Teshnizi S, Tafrihi M, Alavi A, Jafari A, Badri S, et al. [Nurses' knowledge about crisis management and its related factors (Persian)]. Journal of Health and Care. 2011; 13(4):10-8.

[13] Vosoughi Nayeri A, Vosoughi Nayeri M, Golestanifar H, Pahlavanzadeh B, Savadpour MT. [Investigation of army soldiers readiness about health actions in critical circumstances. Case study: Malek Ashtar Military Garrison's (Persian)]. Health in Emergencies and Disasters. 2013; 1(1):77-87.

[14] Miri A, Poursadeghiyan M, Baneshi MM, Biglari H, Yari AR, Khammar A. Study on attitudes of students of Islamic Azad University Tehran Medical Branch toward food safety, 2016. Electronic physician. 2017; 9(5):4289-95. doi: $10.19082 / 4289$ 
